\title{
The Relationship between Iranian EFL Teachers' Creativity and Time Management Skills
}

Hamed Barjesteh*, Sorour Azam Asadpour, Mehdi Manochehrzadeh

Department of English language and Literature, Islamic Azad University, Ayatollah Amoli Branch. Amol, Mazandaran, Iran

Corresponding Author: Hamed Barjesteh, E-mail: ha_bar77@yahoo.com

\section{ARTICLE INFO}

\section{Article history}

Received: November 15, 2017

Accepted: January 14, 2018

Published: March 01, 2018

Volume: 7 Issue: 2

Advance access: February 2018

Conflicts of interest: None

Funding: None

\begin{abstract}
Early research on creativity has illustrated that time is a significant resource education in general and classroom in particular. It is vital for incubation, thus, individuals should be given enough time to do a creative work. The current study sought to uncover the probable relationship between English language teachers' creativity and time management skills. We hypothesized that teachers' creativity plays a role in a number of variables such as age, gender, and teaching experience. It was also surmised that teacher creativity correlates time orientation. To measure teacher creativity, Zhou and George (2001) self-rating creativity was employed. In addition, Trueman and Hartley (1996) time management scale comprising five constructs, production of creative ideas, production of useful ideas, daily planning, confidence in long-term planning, and perceived control of time, were utilized to gauge time orientation. To comply with the objective, a total of 202 intermediate students from three English language institutes took part for the purpose of this study. They were requested to fill out the questionnaires. The data were collected over a period of three weeks. The data were analyzed using Pearson product-moment correlation coefficient to probe the relationship between the variables. The results suggest that teachers with more time orientation incorporate more teaching activities in their classroom. However, the findings revealed that a number of variables like age, gender and teaching experiences were not significant factors for teachers' creativity skills. The findings suggest that a teacher should widen his perception of creativity and repertoire of employing activities in order to maximize students' capacity for novelty The may help language teachers and policy makers bring to a focus on the effects of time management skills and teachers' creativity in the EFL content to achieve a better result in learning process.
\end{abstract}

Key words: Age, Creativity, Efl Teacher, Efl Learner, Gender, Time Orientation, Teaching Experience

\section{INTRODUCTION}

In the late $50 \mathrm{~s}$, the concept of creativity turned to be a hot topic for the research area in the united states. Alex F. Osborn known as the father of creative behavior foundation held many workshops on creativity in education. Similarly, in Russia and Japan, many experts in the field of education endeavored to add a center for creativity in schools so as to explore students' talents and nurture their creativity in school. Today, it is commonly known as the age of innovation and entrepreneurship. Many scientists highlight the role of generosity in creativity. However, one cannot deny the role of parents, teacher, education and environment for nurturing creativity among learners. In the late $90 \mathrm{~s}$, the concept of creativity heralded a movement towards education in general and classroom teaching in particular. The current professional literature reveals that teachers try to teach more creatively and foster children's creativity (Grainger, Goouch \& Lambirth, 2005; Craft, Cremin \& Burnard, 2007).

Similarly, teacher trainers, curriculum developers, and materials developer have been recommended by different gov- ernment reports incorporating more creative approaches and to teach for creativity as well as teach creatively in Iran. As a note of causation, creative teaching and teaching for creativity are different in that the former highlights teacher orientations while the later focus on learner orientation. More precisely, the former seems to engage teachers in creating learning more fruitful and interesting by incorporating imaginative approaches in the classroom. However, the second seems to involve teachers in finding students' creative strengths by nurturing their creativity. There has been considerable research into creative teaching (Beetlestone 1998; Craft, 2001; Jones and Wyse, 2004) in identifying features of creative teaching such as confidence, enthusiasm and commitment, relevance, ownership, innovation, risk taker to name a few.

There is a common consensus among the researchers that creativity plays a pivotal role in human life in general and education in particular. The purpose of the system of education in many countries is to foster learners' creativity (Craft, 2005; Davies, 2006; Stables, 2009). The meaning of 'creativity' has been a controversial issue in such education policies. 
Thus, authors defined the very concept differently (Robinson, 2001; Sefton-Green \& Sinker, 2000) and it tends to be examined less individualistically in more collectivist (Niu \& Sternberg, 2002). Regarding this perception, this directs to a lack of time spent in the classroom on the development of problem-solving skills in some fields. Teachers require being encouraged to investigate new perceptions (Piggott, 2007).

Yusef (2007) examined the new features of learners that can conduct to creative people. Particularly, he believes that children should learn to work in collaborative groups and have availability to high-quality teachers and classroom teaching that is augmented at home. The classroom environment is an important factor in improving creativity in students. Both teachers and students think that the classroom environment enhances creativity when students have choices, different perspectives are proper, self-confidence is cultivated, and students' consistencies and interests are reinforced (Fleith, 2000). Diakidoy and Kanari (1999) concluded similar results in the importance of classroom environment while examining the ideas of student teachers about creativity, creative findings, and factors related to creativity. Creativity was examined as mentioned through artistic and literary activity and observed as a skill that can be taught to students. Eysenck (1995) postulates creativity as a latent feature which is a fundamental issue for creative practices. Likewise, Cummings (1996) illustrated that a person is likely to have a high creative output if she has the personality features of a creative person. One limitation with the research on personality and creativity is that it is not area specific but rather involves persons in general.

Current researches, however, offer the domain-specificity of personality variables due to creativity (e.g. Baer, 1998). Feist (1998) discussed that, although personality situations do orderly and predictably relate to creative success in art and science, there is a common consistency of these personality measures of creative people; creative artists and creative scientists do not have the same personality features. The previous study on creativity has explained that time is an important resource (Wallas, 1926). Time; for example, is significant for incubation. The individual should have enough time to perform a creative work (Runco, 2007). According to Mednick (1962), fundamental ideas should be outmost and are usually far away from the basic problem or initial idea. This farness requires time. It takes time to move from idea to idea, and to find the outmost relation. Although time has been repeatedly used as a variable or as an implied area in creativity study, no empirical studies have been examined knowledge about the relation of time management with creativity. Empirical evidence on the relationship between creativity and time has been limited basically to the effects of time pressure to creative outcomes in organizations (Amabile, Lazenby, \& Herron, 1996; Simpson, Hadley, Kramer, \& Fleming, 2002).

Researchers have examined the relationship between individual creativity and individual time management practices. Following the importance of creativity and time management, the gap in study on the relationship between individual creativity and time management practices makes a significant problem. In addition, there are different diffi- culties for teachers to handle their time because of the restriction they have in the school or institutions. They can be creative in some English institutes and use some tasks they think can be effective but some institutes have a fixed rule that make teachers restrict to use creativity. In fact, all teachers should reconcile their strategies and methods regarding the administrators and managers of the institutes and don't have enough time to utilize more tasks. The same rule can be observed in schools and most English teachers have to utilize the traditional methods and some prefabricated statements and can't observe any creativity regarding the limited time they have.

A case study conducted by Grainger, Barnes, and Scoffham (2006) revealed a close relationship between teacher and learner creativity. This study revealed that the three aspects of creative practice are interrelated to each other. More specifically, teachers' personal characteristics, their pedagogy and the class/school ethos are interrelated to one another (see figure 1).

Teachers must balance the demands of increasing accountability, and limited time with the need for creativity and help students maximize language achievement. Teachers' creativity and time orientation may lead better result in education. Education should be treated as a strategic agent for creativity by the creation of a well-educated teaching, sufficiently equipped with the knowledge needed to competently and competitively solve the development challenges in teaching, restructure and transform qualitatively with a focus on promoting creativity and problems solving. This study aims to fill the gap in the existing literature to manage teachers' time efficiently so as to improve the performance of language teachers in educational setting. Time Management helps the researchers to know what to do now, what to delegate, what to dump and what to postpone and all of these are required to be creative in teaching which leads to student achievement. The purpose of this exploratory study was to investigate the relationship between time management skills and language teachers' creativity. To undertake the study, a number of subscales for the corresponding variables were taken into account. More precisely, this study was delimited to the following factors with the hope to find the possible

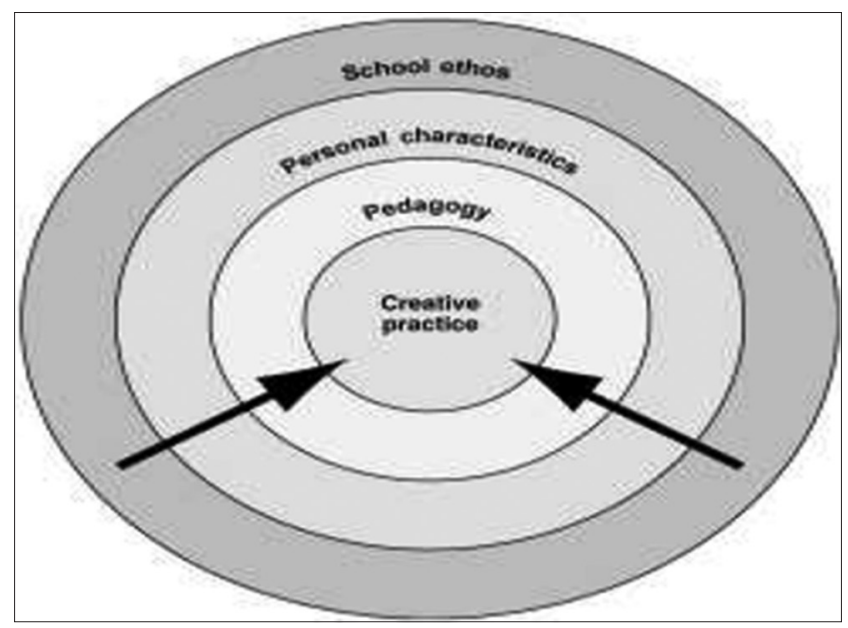

Figure 1. A framework for creative teaching 
nexus among the factors like the time management skills namely, production of creativity, production of useful ideas, daily planning subscale, confidence in long-term planning, and perceived control of time. In this regard, the following research questions were proposed:

1) Is there any significant relationship between EFL teacher creativity and their time orientation?

2) Is there any significant relationship among teacher creativity, age, gender, and teaching experience?

3) Is there any significant relationship among teachers' time management, age, gender and teaching experience?

\section{METHODOLOGY}

\section{Participants}

The participants of the present study comprised of 202 Iranian students, male $=76$ and female $=126$. They were from different levels of education from high school and university. They were recruited from different English language institute who were from the same level of English language proficiency despite the difference in their education and age range. The selection of the participants was notified by consent from the respondents highlighting the volunteering nature and emphasizing the ethical considerations like anonymity and confidentiality. It was attempted to choose the participants at the same level of language proficiency. In so doing, a convenience sampling procedure was used to uncover the nexus between teacher creativity and the time management skill. To undertake the study, all intermediate English language students enrolled in English language classes were invited for the purpose of this study. They were all native speakers of Persian who had a minimum of four years of experience in learning English from different language institute. Their ages ranged from 25 to 40 , the majority were 35 .

\section{Instruments}

Two instruments utilized for the purpose of this study. What follows describes each instrument in detail:

\section{Time management scale (TMS)}

The scale was created by combining questions from the work of Trueman and Hartley (1996). This questionnaire comprised of 18 items in a Likert Scale format and with three sub-scales including (a) daily planning subscale, (b) confidence in long-term planning, and (c) perceived control of time subscale. To check the reliability of the questionnaire, it was already piloted among 58 intermediate students at different English language institutes. TMS enjoyed a reliability index of.88. In addition, the content was assessed by three experts in the field to ensure the content validity of the instrument.

\section{Self-rating of creativity (SRC)}

Self-rating of creativity was assessed using eight items from the creativity scale developed by Zhou and George (2001) which aimed to assess students' beliefs in the production of novel ideas, creative solutions to problems, new and practical ideas to improve performance, and new ways to increase the quality of project assignments. To examine the reliability of the questionnaires, they were administered to a pilot group which was smaller than the target participants. Twenty-six learners (18 females and 8 males) were randomly selected for piloting. The questionnaire enjoyed a high-reliability index of.90.

\section{PROCEDURE}

This study sought to investigate the probable relationship between teachers' creativity and time management. To conduct the study, two questionnaires including time management and self-rating creativity were administered among the learners. Before administering the questionnaires among the subject pool, they were checked out for the reliability in the EFL context of Iran. Using Cronbach alpha, both questionnaires enjoyed a reliability of.72 and.78. In addition, the result was assessed by three experts in the field to ensure the content validity. After ensuring the reliability and validity in the EFL context of Iran, the questionnaires were distributed among all intended participants. A total of 426 questionnaires were distributed over a period of 21 days. The researchers took the responsibility of handing out the questionnaires. They were distributed in person, by email or via telegram to the target participants. They were requested to answer as honestly as possible. They were informed about the main objective of the present study and how their response could change the findings of the present study. They were also ensured the privacy and the confidentiality of the all the data. After clarifying the main goals and students' focal role in the study, some of them refused to take part in the study. After collecting the questionnaires, a total of 404 questionnaires seemed to be qualified for analysis by the researchers. They were collected in a period of three weeks. Only 22 questionnaires were not completed appropriately. The others illustrated a valid response rate of $95.10 \%$. This valid response is incongruence with Cohen, Manion and Morrison (2000) adequate range between $40 \%$ and $50 \%$.

\section{RESULT}

The first research question sought to investigate whether there is a relationship between teacher's time orientation and teacher creativity. First, descriptive statistics of each variable was run. Table 1 below shows the result of descriptive statistics for the time orientation and the corresponding scales.

Table 1 shows that the least range in daily planning is 13 , the most range of daily planning is 22 , and mean and standard deviation are 18.65 and 2.41 respectively. In addition, the least and most range of confidence in long-term planning are 14 and 26 respectively. Also, the mean and standard deviation of time orientation are 21.03 and 2.954. The perceived control of time has the least and most range of 10 and 25. Furthermore, its mean and standard deviation are 21.16 and 2.41 respectively. To provide a better schematic representation the following figure represents time orientation subscales. 
As indicated in the figure 2 the perceived control of time subscale has the higher mean score than the other subscales. It reveals that teachers can develop their teaching creativity when they control and manage the time.

Table 2 represents that the least and the most range of daily planning behaviors are 9 and 20 respectively and the corresponding mean and standard deviation are 16.72 and 2.956. The least and most range of confidence on long-range planning is 10 and 20 respectively with the mean and standard deviation of 15.47 and 2.528 .

Figure 2 represents the mean rank of teacher creativity. The figure represents that daily planning highlights higher mean rank than confidence on long-range planning. This implies that due to the dynamicity nature of the classroom and learners needs any predetermined planning for the classroom is not advisable.

In order to probe the probable relationship between teacher creativity and time orientation, Pearson product-moment correlation coefficient was run. The results are presented below in Table 3 .

As indicated in the table 3, there is a relatively strong relationship between TMS and SRC. This correlation reveals a significant meaningful relationship since the sig. value is below. 05 .

To examine the probable relationship between the components of TMS with teacher creativity a Pearson-product moment correlation was run. Table 4 below represents the results.

As indicated in Table 4 are a meaningful relationship among time orientation and the three subscales including

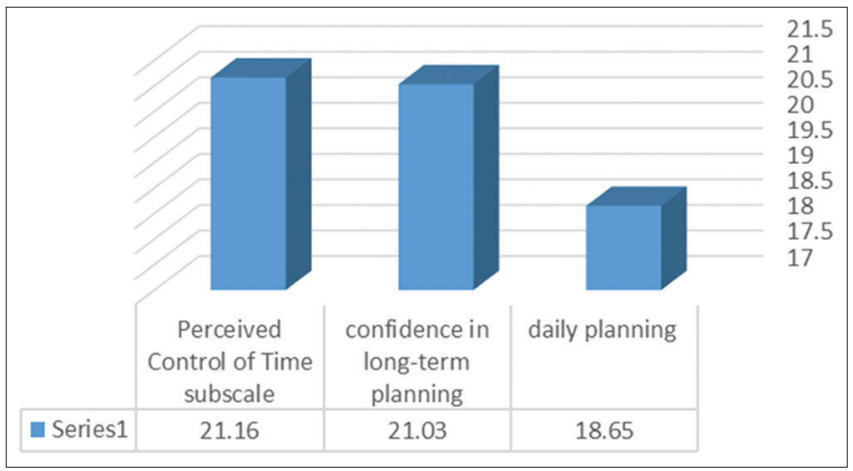

Figure 2. The mean rank of time orientation subscales daily planning (0.80), confidence in long-term planning (0.66) and perceived control of time (0.80). Furthermore, there are significant relationships among teacher creativity with its two subscales including daily planning behavior (0.70) and confidence on long-range planning (0.70). To provide a better schematic representation, Figure 3 below illustrates the findings.

The second aim of this study was to explore the probable relationship among teacher creativity, age, gender and teaching experience. In order to answer this research question, Pearson correlation was conducted. Table 4 illustrates the results.

Table 4 reveals that there isn't any significant relationship between gender and teacher creativity. In addition, there isn't any significant relationship between age and teacher creativity. Similarly, there is not a significant relationship between teaching experience and teacher creativity.

In order to find the relationship among teachers' time management, age, gender and teaching experience, another Pearson correlation coefficient was run. The results are represented in Table 5.

Table 5 illustrates that there is not a meaningful relationship between TMS and gender, age, ae well as teaching experience.

\section{DISCUSSION}

The present study aimed at finding the relationship between EFL teachers' creativity and the time management scales. The findings revealed that EFL teachers who use more time management skills, like daily planning, confidence in long-term planning, and perceived control of time, in their classroom

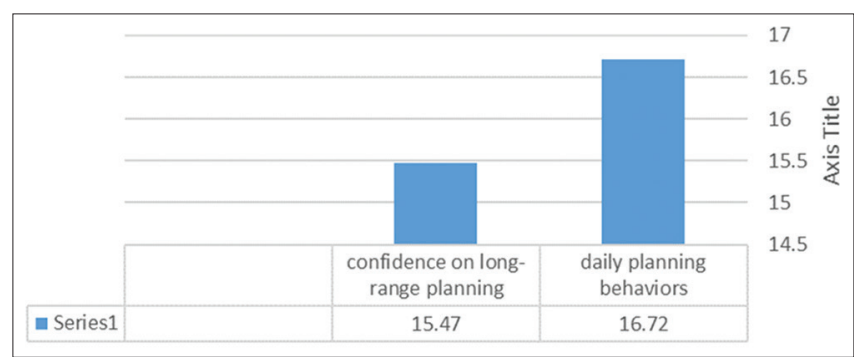

Figure 3. The mean rank in teacher creativity subscales

Table 1. Descriptive statistics of time orientation and the subscales

\begin{tabular}{lcccccc}
\hline Time orientation & N & Range & Minimum & Maximum & Mean & Standard deviation \\
\hline$* 1$ & 202 & 9 & 13 & 22 & 18.65 & 2.41 \\
2 & 202 & 12 & 14 & 26 & 21.03 & 2.95 \\
3 & 202 & 15 & 10 & 25 & 21.16 & 2.95 \\
\hline
\end{tabular}

* 1=Daily planning; $2=$ Confidence in long term planning; $3=$ Perceived control of time

Table 2. Descriptive statistics of teacher creativity and its subscales

\begin{tabular}{lcccccc}
\hline SRC & N & Range & Minimum & Maximum & Mean & Standard deviation \\
\hline Daily planning behaviors & 202 & 11 & 9 & 20 & 16.72 & 2.956 \\
Confidence on long-range planning & 202 & 10 & 10 & 20 & 15.47 & 2.528 \\
Self-rating creativity & 202 & 18 & 22 & 40 & 32.19 & 4.115 \\
\hline
\end{tabular}


incorporative creative and useful idea in their classroom. However, this relationship was not significant among a number of variables like age, gender and teaching experiences. In other words, factors like job seniority, gender and age do not affect teachers' creativity skills. The results indicated a direct correlation between effective time management and the

Table 3. Pearson correlation coefficient between teacher creativity and time orientation

\begin{tabular}{lcc}
\hline & $\begin{array}{c}\text { Time } \\
\text { management } \\
\text { scale }\end{array}$ & $\begin{array}{c}\text { Self-rating } \\
\text { creativity }\end{array}$ \\
\hline Time management scale & 1 & $0.623^{* *}$ \\
Pearson correlation & 202 & 0.000 \\
Sig. (2-tailed) & & 202 \\
N & $0.623^{* *}$ & 1 \\
Self-rating creativity & 0.000 & \\
Pearson correlation & 202 & 202 \\
Sig. (2-tailed) & & \\
N &
\end{tabular}

**Correlation is significant at the 0.01 level (2-tailed). success in creative work. In this study, time management referred to the planning behaviors that simplified productivity and could restrict stress; contain preferences of activities and management of possible confusions which is negatively related to the study of Zampetakis, Bouranta, and Moustakis (2010) which stated time pressures experienced by individuals negatively correlated with production in creative problem solving. Therefore, those people who had the ability to man-

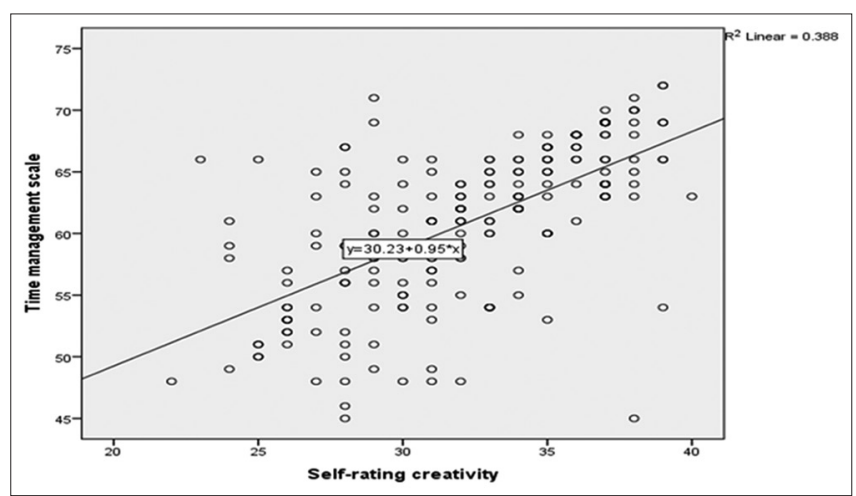

Figure 3. The relationship between teacher creativity and time orientation

Table 4. Pearson product-moment correlation coefficient between time orientation and teacher creativity

\begin{tabular}{lccccccccc}
\hline Variables & $\mathbf{M}$ & SD & Skewness & Kurtosis & $\mathbf{1}$ & $\mathbf{2}$ & $\mathbf{3}$ & $\mathbf{4}$ & $\mathbf{5}$ \\
\hline 1 & 60.84 & 6.285 & -0.507 & -0.576 & 1 & $0.62^{* *}$ & $0.80^{* *}$ & $0.66^{* *}$ & $0.80^{* *}$ \\
2. & 32.19 & 4.115 & -0.200 & -0.866 & $0.62^{* *}$ & 1 & $0.58^{* *}$ & $0.33^{* *}$ & $0.51^{* *}$ \\
3. & 18.65 & 2.414 & -0.478 & -0.909 & $0.80^{* *}$ & $0.58^{* *}$ & 1 & $0.27^{* *}$ & $0.63^{* *}$ \\
4. & 21.03 & 2.954 & -0.294 & -0.744 & $0.66^{* *}$ & $0.33^{* *}$ & $0.27^{* *}$ & 1 & $0.19^{* *}$ \\
5. & 21.16 & 2.957 & -1.126 & 1.606 & $0.80^{* *}$ & $0.51^{* *}$ & $0.63^{* *}$ & $0.19^{* *}$ & 1 \\
\hline
\end{tabular}

1. Production of creative ideas; 2. Production of useful ideas; 3.Daily planning; 4. Confidence in long-term planning; 5 . Perceived control of time ${ }^{* *}$ Correlation is significant at the 0.01 level (2-tailed)

Table 5. The Pearson correlation coefficient among teacher creativity, age, gender and teaching experience

\begin{tabular}{|c|c|c|c|c|}
\hline & Gender & Age & Teaching experience & Self-rating creativity \\
\hline \multicolumn{5}{|l|}{ Gender } \\
\hline Pearson correlation & 1 & $0.330^{* *}$ & $0.405^{* *}$ & 0.021 \\
\hline Sig. (2-tailed) & & 0.000 & 0.000 & 0.770 \\
\hline $\mathrm{N}$ & 202 & 202 & 202 & 202 \\
\hline \multicolumn{5}{|l|}{ Age } \\
\hline Pearson correlation & $0.330 * *$ & 1 & $0.503^{* *}$ & -0.118 \\
\hline Sig. (2-tailed) & 0.000 & & 0.000 & 0.095 \\
\hline $\mathrm{N}$ & 202 & 202 & 202 & 202 \\
\hline \multicolumn{5}{|l|}{ Teaching experience } \\
\hline Pearson correlation & $0.405^{* *}$ & $0.503^{* *}$ & 1 & -0.123 \\
\hline Sig. (2-tailed) & 0.000 & 0.000 & & 0.080 \\
\hline $\mathrm{N}$ & 202 & 202 & 202 & 202 \\
\hline \multicolumn{5}{|l|}{ Self-rating creativity } \\
\hline Pearson correlation & 0.021 & -0.118 & -0.123 & 1 \\
\hline Sig. (2-tailed) & 0.770 & 0.095 & 0.080 & \\
\hline $\mathrm{N}$ & 202 & 202 & 202 & 202 \\
\hline
\end{tabular}

**Correlation is significant at the 0.01 level (2-tailed) 
Table 5. Pearson correlation among teachers' time management, age, gender and teaching experience

\begin{tabular}{|c|c|c|c|c|}
\hline & Gender & Age & Time management scale & Teaching experience \\
\hline \multicolumn{5}{|l|}{ Gender } \\
\hline Pearson correlation & 1 & $0.330 * *$ & 0.006 & $0.405^{* *}$ \\
\hline Sig. (2-tailed) & & 0.000 & 0.927 & 0.000 \\
\hline $\mathrm{N}$ & 202 & 202 & 202 & 202 \\
\hline \multicolumn{5}{|l|}{ Age } \\
\hline Pearson correlation & $0.330 * *$ & 1 & -0.127 & $0.503 * *$ \\
\hline Sig. (2-tailed) & 0.000 & & 0.072 & 0.000 \\
\hline $\mathrm{N}$ & 202 & 202 & 202 & 202 \\
\hline \multicolumn{5}{|c|}{ Time management scale } \\
\hline Pearson correlation & 0.006 & -0.127 & 1 & $-0.159 *$ \\
\hline Sig. (2-tailed) & 0.927 & 0.072 & & 0.024 \\
\hline $\mathrm{N}$ & 202 & 202 & 202 & 202 \\
\hline \multicolumn{5}{|l|}{ Teaching experiance } \\
\hline Pearson correlation & $0.405 * *$ & $0.503 * *$ & $-0.159 *$ & 1 \\
\hline Sig. (2-tailed) & 0.000 & 0.000 & 0.024 & \\
\hline $\mathrm{N}$ & 202 & 202 & 202 & 202 \\
\hline
\end{tabular}

**Correlation is significant at the 0.01 level (2-tailed), *Correlation is significant at the 0.05 level (2-tailed)

age time and were learning-oriented used efficient strategies for creative problem solving.

The findings revealed that time pressure is harmful to creativity. It is possible that the feeling of having control over one's time, i.e. perceived control of time, correlated to creativity assesses. Although, previous theory and research has offered that time management skills may be useful for creative results, no practical surveys endeavored to connect creativity and time management which is on the contrary of the current study. Glassman (1986) who conclude that teachers with the time pressure face problem in producing novel ideas. Likewise, Feist (1998) discussed about the consistency of the personality measures of creative individuals. This refers that a measure of the creative personality will represent lower correlations with time management behaviors compared to a measure that produce new and beneficial perceptions which is not in congruent with the present research. In addition, Darini, Pazhouhesh, and Moshiri (2011) conducted similar study among 346 undergraduate students. The findings represented a positive correlation between time management skills such as, daily planning, long-term planning, perceived control of time, tenacity, and a preference for organization, and personal creativity. They concluded that time management skills may be necessary for the efficient examination of creative perceptions.

A number of studies indicate that in order to enhance learners' creativity, teachers need to develop an awareness of students' needs by involving their students in their own learning. For example, in their evaluation of eleven case study schools involved in Creative Partnerships projects, Sharp, Blackmore, Eames, Easton, and Filmer-Sankey (2005) recognized a need for an awareness of students' multiple intelligences and different learning styles amongst staff. Similarly, Jeffrey's (2006) Creative Learning and Student Perspectives (CLASP) project study found a common pedagogic discourse across European partners by those concerned to engage the agency of students creatively in their own learning; whilst Bancroft, Fawcett, and Hay (2008) observed the quality of attention given to learners' needs by adults involved in the creativity project to foster child-initiated learning that was also adult-framed. From their study of eight collaborating teachers in four school sites, Cochrane and Cockett (2007) observed a shifting balance between structure and freedom in their approach to curriculum planning, both at the medium and short-term levels. Similarly, the evaluation of eleven case studies of Creative Partnership projects by Sharp, Pye, Blackmore, Eames, Easton, and Filmer-Sankey (2005) identified a shift towards less prescription in lesson planning; allowing more room for individual pupil responses. Pan-European context, Jeffrey (2006) also observed teachers constructing 'real and critical events' as part of their lessons, demonstrating a shift towards novelty and authenticity in their curriculum offering to pupils.

\section{CONCLUSION}

This study was an attempt to explore the possible nexus between EFL teachers' creativity and time management skill. A straight forward conclusion for the present study is that creative practice is a multilayer facet which encompasses various dimensions. More precisely, this study reveals that individual creativity was significantly related to a number of time management behaviors namely, daily planning and confidence on long-range planning, as well as time attitudes such as perceived control of time, tenacity and preference for disorganization. Correlations were found to be stronger when creativity was considered as product oriented focusing on the extent to which outcomes are useful and novel as compared to the results obtained with a general creative personality construct. This implies that planning daily activities, 
prioritizing them, and having confidence on long-range planning are more relevant to the production of novel and useful ideas. In other words, the findings revealed that time management behaviors may be necessary for the effective exploitation of creative ideas. In seeking to become a creative teacher, a teacher should widen his perception of creativity and repertoire of employing activities so as to foster learners' capacity for novelty. A teacher should take the advantage of his autonomy and various learning contexts. As Joubert (2001, p. 21) postulates "creative teaching is an art." One cannot teach teachers didactically how to be creative; there is no fail-safe recipe or routine. Some strategies may help to promote creative thinking, but teachers need to develop a full repertoire of skills which they can adapt to different situations. What is clear from this study is that a creative teacher should be well aware of novelty in themselves and search to nurture such a mindset for the students. What implies from this general conclusion is that within the notion of creativity a number of concept are embedded, autonomy, flexibility, personal quality, ethos, to name a few.

\section{REFERENCES}

Amabile, T. M., Lazenby, J., \& Herron, M. (1996). Assessing the work environment for creativity. Academy of Management Journal, 39, 1154-1184. doi.org/10.1002/j.2162-6057.2005.tb01247.x

Baer, J. (1998). The case for domain specificity of creativity. Creativity Research Journal, 11(2), 173-177. doi.org/10.1037/a0022834.

Britton, B. K., \& Tesser, A. (1991). Effects of time-management practices on college grades. Journal of Educational Psychology 83, 405-410. doi.org/10.1002/jocb.36

Cohen, L., Manion, L., \& Morrison, K. (2000). Research methods in education ( $5^{\text {th }}$ ed.). London: Routledge-Falmer, Psychology Press.

Craft, A., McConnon, L., \& Matthews, A. (2012). Child-initiated play and professional creativity: Enabling fouryear olds' possibility thinking. Thinking Skills and Creativity 7(1), 48-61. doi: http://dx.doi.org/10.1016/j. tsc. 2011.11 .005

Cumming, J. (1996). Contextualized Performance: Reframing the skills debate in research education. Studies in Higher Education, 35(4), 405-419.

Darini, M., Pazhouhesh, H., \& Moshiri, F. (2011). Relationship between employee's innovation (creativity) and time management. Procedia - Social and Behavioral Sciences, 25(1), 201-213. doi: 10.1016/j.sbspro.2011.10.541

Davies, T. (2006). Creative teaching and learning in Europe: promoting a new paradigm. The Curriculum Journal, 17(1), 37-57.

Diakidoy, I., \& Kanari, E. (1999). Student teachers' beliefs about creativity. British Educational Research Journal, 25(2), 225.

Eysenck, H. (1996). The Measurement of Creativity. In Boden, M. (Ed.), Dimensions of Creativity (pp. 199-
242). Cambridge, MA: MIT Press.

Feist, G. J. (1998). A meta-analysis of personality in scientific and artistic creativity. Personality and Social Psychology Review, 2(4), 290-309. hdoi. org/10.1177/0305735608100374

Fleith, D. (2000). Teacher and student perceptions of creativity in the classroom environment. Roeper Review, 22(3), 148. doi.org/10.1007/s10972-006-9009-4

Glassman, E. (1986). Managing for creativity: Back to basics in R\&D. Management 16(2), 175-183.

Grainger, T, Barnes, J., \& Scoffham, S. (2006). Creative teaching for tomorrow. Research report for creative partnerships.

Jeffrey, B., \& Craft, A. (2004). Teaching creatively and teaching for creativity: Distinctions and relationships. Educational Studies, 50(1), 77-87. doi: 10/1080.0305569032000159750.

Joubert, M. M. (2001) The art of creative teaching: NACCCE and beyond. In A. Craft, B. Jeffrey, \& M. Liebling (Eds.), Creativity in Education (pp. 17-34). London: Continuum.

Macan, T. H. (1994). Time management: Test of a process model. Journal of Applied Psychology, 79(3), 381-391. doi.org/10.1207/s15326934crj1801 10Sternberg,

Mednick, S. A. (1962). The associative basis for the creative process. Psychological Bulletin, 69, 220-232.

Robinson, K. (2001). Out of Our Minds: Learning to be Creative. Oxford. Capstone.

Runco, M. A. (2007). Creativity. Theories and themes: Research, development, and practice. Amsterdam: Elsevier Academic Press.

Sefton-Green, J. (2000). From Creativity to Cultural Production: shared perspectives. In J. Sefton-Green, and R. Sinker, (Eds.), Evaluating Creativity: Making and learning by young people (pp. 215-230). London: Routledge.

Sharp, C., Pye, D., Blackmore, J., Eames, A., Easton, C., \& Filmer-Sankey, C. (2005). National evaluation of creative partnerships. Available at http://www.nfer.ac.uk/ nfer/publications/CPS02/CPS02.pdf.

Stables, K. (2009) Educating for environmental sustainability and educating for creativity: Actively compatible or missed opportunities? Int J Technol Des Educ, 19, 199-219

Trueman, M., \& Hartley, J. (1996). A comparison between the time management skills and academic performance of mature and traditional-entry university students. Higher Education, 32, 199-215.

Wallas, G. (1926). The art of thought. New York: Harcourt, Brace.

Zampetakis, L. A., \& Moustakis, V. (2006). Linking creativity with entrepreneurial intention: A structural approach. International Entrepreneurship and Management Journal, 2(3), 413-428.

Zhou, J., \& George, J. M. (2001). When job dissatisfaction leads to creativity: Encouraging the expression of voice. Academy of Management Journal, 44(4), 582-696. 